\title{
The Commonwealth and the Edinburgh CHOGM: Challenges and Opportunities
}

\author{
Alison Duxbury
}

$\mathrm{F}$ ToR a few days during the 1997 Commonwealth Heads of Government Meeting (CHOGM) held in Edinburgh, the Commonwealth of Nations received a modicum of media attention in Australia. Reports and editorials focused on Prime Minister John Howard's success in achieving recognition for Australia's position on greenhouse gas emissions, the advantages of Commonwealth membership to Australia and British Prime Minister Tony Blair's ability to use CHOGM to assert Britain's international role. But apart from the interest generated by the biennial meeting, little recognition is given to the multifarious functions of an organisation which has been described as 'the world's oldest and least understood political association of sovereign states' (McIntyre, 1991:1). Readers may be surprised to learn that the Commonwealth now comprises 54 member states and approximately 1.7 billion people, that there are over 200 formal and informal organisations with the title 'Commonwealth', and that the organisation plays an active role in monitoring the elections of member states, including the 1997 poll in Papua New Guinea.

This article traces the evolution of the Commonwealth through the CHOGMs held in the 1990s, focusing on the most recent meeting in Edinburgh. It examines the development of the Commonwealth as an international organisation, the current emphasis on trade and investment and its stance on human rights. Finally, it analyses the place Australia sees for both CHOGM and the wider Commonwealth in its foreign policy in the 1990s.

\section{Commonwealth Heads of Government Meetings in the 1990s}

As the principal decision-making body of the Commonwealth and its most public face, CHOGM reflects two fundamental principles of the organisation: consensus decision-making and non-interference in the domestic affairs of member states. ${ }^{1}$ In the past, the leaders have largely refrained from condemning the actions of individ-

\footnotetext{
${ }^{1}$ These two principles are contained in The Agreed Memorandum on the Commonwealth Secretariat of 1965, the document which established the Secretariat as the administrative organ of the association. Paragraph 4 of the Memorandum provides that 'the Commonwealth is not a formal organisation. It does not encroach on the sovereignty of individual members. Nor does it require its members to reach collective decisions or to take united action'.
}

Alison Duxbury is Lecturer in Law at Monash University. 
ual member countries, preferring to confine their recommendations to broad issues affecting the membership as a whole. However, in the 1990s there appears to have been a shift away from these traditional principles in favour of creating an organisation with articulated standards and procedures for ensuring compliance.

Since the first CHOGMs held in the 1960s (replacing the Commonwealth Prime Ministers' Meetings of the 1940s and 1950s), the communiqués (the only official records of discussions) have demonstrated the Commonwealth's engagement with a variety of international issues. This trend has continued in recent years with the 1991 communique revealing a discussion of human rights, Southern Africa, the Middle East, reforms in Eastern Europe, the environment, and women and structural adjustment. More important, at the 1991 meeting in Harare the leaders enunciated a set of human rights standards in the Harare Commonwealth Declaration, the most comprehensive statement of rights in the Commonwealth to date. ${ }^{2}$ The Declaration reaffirms the voluntary nature of the association and the principles of cooperation and consultation, and recognises that the 'special strength of the Commonwealth lies in the combination of the diversity of its members with their shared inheritance in language, culture and the rule of law' (para. 3). In addition, the Heads of Government pledged their commitment to focus on democracy, fundamental human rights and sustainable development (para. 9). The centrality of the Harare Declaration to future Commonwealth action has been highlighted by the Commonwealth Secretary-General, who has described it as the organisation's 'mission statement' for the 1990s and beyond (Anyaoku, 1996).

The second CHOGM of the decade, held in Limassol in 1993, was described as a 'somewhat muted summit' (Ingram, 1994:13) with some leaders absent because of other commitments. Despite this assessment, the official documents issued at the meeting confirmed that the leaders judged that human rights and economic development were crucial issues within the Commonwealth's sphere of competence. The Limassol Communiqué reinforced the importance of the Harare Declaration by linking Cameroon's membership to the establishment of a democratic system consistent with the principles articulated at the previous CHOGM. The leaders also explicitly based South Africa's readmittance to the organisation on the 'nonracial and democratic' elections scheduled to be held the following year (para. 26). Thus, by 1993 it appeared that 'democracy' was to be a key factor in assessing future membership applications. In addition to the communiqué, the leaders issued the Limassol Statement on the Uruguay Round, urging the need for a strong multilateral trading system as the best guarantee that all countries would share in economic growth and development. This statement reflects the Commonwealth's concern with the economic future of member states, a concern subsequently repeated in the Edinburgh Commonwealth Economic Declaration adopted in 1997.

\footnotetext{
${ }^{2}$ Prior to 1991, the leaders had adopted the Declaration of Commonwealth Principles (1971) which recognised 'equal rights for all citizens regardless of race, colour, creed or political belief, and their inalienable right to participate by means of free and democratic political processes in framing the society in which they live'.
} 
The renewed program of French nuclear testing in the South Pacific Ocean and the impending death sentence imposed on Ken Saro-Wiwa in Nigeria dominated publicity about the Auckland CHOGM in 1995. Yet the meeting discussed a number of other issues, including ratification of the Chemical Weapons Convention, Hong Kong, Cyprus, development assistance, money laundering and small states. The leaders gave weight to the human rights principles expressed in the Harare Declaration by approving the Millbrook Action Programme, which included specific measures to be pursued in response to violations of the Harare Declaration. Designed to provide a method of implementing the Harare human rights principles, the measures outlined in the Millbrook Programme ranged from a public expression of disapproval by the Secretary-General to suspension of participation in Commonwealth meetings. An important aspect of the Programme was the establishment of the Commonwealth Ministerial Action Group (CMAG) to deal with serious and persistent violations of the Harare Declaration, demonstrating for the first time that the Commonwealth was willing to institute enforcement procedures to ensure compliance with confirmed standards. The subsequent decision to use these powers and suspend Nigeria from membership for its human rights violations reinforced the view that the organisation was moving away from its traditional reliance on friendly cooperation towards a more rules-based approach to its decisionmaking.

The suspension of Nigeria and the decision to admit Mozambique to the organisation at the Auckland CHOGM suggested further changes in the character of the Commonwealth as an international organisation. First, the specific mention of Nigeria, The Gambia and Sierra Leone in the communiqué (paras. 10-12) emphasised that the leaders were willing to cite problems in individual countries if not discuss their political situation in detail. Second, as The Gambia did not participate in the decision to suspend Nigeria, it would appear that consensus decision-making is no longer a requirement in the Commonwealth of the 1990s. Finally, the presence of Mozambique at the meeting, the first country to be admitted with no historical links to Britain, demonstrated that the traditional criteria for membership (that the country be a former British dependant or dependant of another Commonwealth member) may no longer apply. This prompted the leaders to establish the Intergovernmental Group on Criteria for Commonwealth Membership to advise on potential membership principles and to report at the next meeting. Thus, in 1995 the Commonwealth was not only willing to discuss the issues it considered important, but it was also equipped to ensure compliance with its articulated norms as an aspect of its role as an international organisation.

\section{The Edinburgh CHOGM}

The Edinburgh CHOGM in October 1997 was the first held in Britain for 20 years. ${ }^{3}$ Forty-three heads of govenmment and heads of state were present at the

${ }^{3}$ Documents from the Edinburgh CHOGM can be found at: hup://www.chogm97.org/ 
meeting as well as representatives from the eight other countries entitled to attend. Unusually, the meeting was directly addressed by the Queen at the opening ceremony, as well as the Prime Minister of India in order to acknowledge the celebration of 50 years of Indian independence. In his opening statement, the Commonwealth Secretary-General, Chief Emeka Anyaoku, listed four main agenda items for the meeting: trade and investment (the theme of the summit), political subjects such as CMAG's report on the position of Nigeria, the vulnerability of small states, and the functional cooperation programs of the Commonwealth Secretariat, the Commonwealth Foundation and the Commonwealth of Learning. Three issues arise from the Edinburgh CHOGM: the development of the Commonwealth as an international organisation, the theme of trade and investment and the evolution of the organization's human rights policy.

\section{Development of the Commonwealth as an International Organisation}

The essential characteristics of a public international organisation include its foundation agreement, its membership of states and the presence of an independent organ (in the case of the Commonwealth, the Secretariat in London). While there has been some debate about the exact status of the Commonwealth, writers have pointed to its international personality and ability to take initiatives on its own behalf to establish its position as an international organisation. ${ }^{5}$ The most significant addition to the Commonwealth's organisational structure in 1997 concerned the membership criteria for states applying to join. The initial report of the Intergovernmental Group on Criteria for Commonwealth Membership recommended that eligibility for membership be based on direct or indirect British rule or administrative links with another Commonwealth country. It also recommended that, prior to applying for membership, a country should adhere to the Harare principles of 'democracy, good government and human rights' (Collinge, 1996:285). These criteria were endorsed in paragraph 20 of the Edinburgh Communiqué where the Heads of Government stated:

that in order to become a member of the Commonwealth, an applicant country should, as a rule, have had a constitutional association with an existing Commonwealth member; that it should comply with Commonwealth values, principles and priorities as set out in the Harare Declaration; and that it should accept Commonwealth norms and conventions.

These criteria demonstrate that the Commonwealth does not envisage itself developing into a universal organisation, seeking to have all states as members. Instead,

\footnotetext{
${ }^{4}$ Schermers and Blokker (1995:23) define international organisations as "forms of cooperation founded on an international agreement creating at least one organ with a will of its own, established under international law'. They recognise that one element which all public international organisations have in common is member states.

${ }^{5}$ See for example Chan (1992), Dale (1982) and Duxbury (1997).
} 
it will only accept members ('as a rule') from a specified or closed group of states which fulfil certain standards. The most significant of these criteria concern the application of the Harare Declaration. Whereas in the past there was no compulsion to sign any constituent instruments prior to joining the Commonwealth, the Heads of Government in 1997 have explicitly recognised that potential applicants will be assessed according to the standards adopted by the organisation as a whole at the Harare meeting.

The Commonwealth's commitment to these precepts was demonstrated in 1997 by its stance on the acceptance of new members and the readmittance of a previous member. The Heads of Government in the Edinburgh Communiqué affirmed that the applications by Palestine, Rwanda and Yemen would be reviewed according to the agreed membership criteria (para. 21). Additionally, Palestine's application would be subject to the attainment of state sovereignty under the Oslo Accords. In September 1997, Fiji was readmitted into the Commonwealth after its membership had lapsed in 1987 following the rescission of its independence constitution and the declaration of a republic. The drafting of Fiji's new constitution followed a 15-month Constitutional Review Commission which recommended a multi-ethnic government based on the Westminster system (Alley, 1997:248). The link between the Harare principles and the new constitutional arrangements was reinforced by the Commonwealth Secretariat's press release announcing the readmittance of Fiji 'now that a new constitution has been approved which enjoys national consensus and which conforms with the Commonwealth's Harare principles'. This use of human rights standards in determining membership applications confirmed the trend, indicated at Auckland, that the Commonwealth was willing to dispense with its conventional policies in order to achieve certain goals.

The articulation of membership criteria and the admittance of new members raises the question of the Commonwealth's role as an international organisation in a world of many regional and international associations. As a smaller representative body than the United Nations, the Commonwealth should ensure that it focuses its efforts on areas where it has a significant comparative advantage. The importance of regional (or, in the case of the Commonwealth, transregional) associations in maintaining international peace and security is explicitly recognised in Chapter VIII of the United Nations Charter. The Commonwealth perceives that its ability to raise a consensus on key issues lies in the common legal, administrative and political traditions shared by its members and the use of English as a working language. But if the organisation continues to expand its membership beyond the 'British Empire' it may find that this comparative advantage is diminished. Thus, if the Commonwealth is to retain an independent and uscful role in the international community it must ensure that the adoption of membership standards enhances rather than dilutes its effectiveness.

\section{Trade, Investment and Development}

In her 1995 discussion paper Economic Opportumities for Britain and the Commonwealth, Katharine West suggests that outdated stereotypes were the main rea- 
son why Commonwealth members have neither perceived nor acted upon their full range of economic opportunities. This has meant that the membership has failed to appreciate the value of transregionalism (as opposed to regionalism) and failed to realise the potential offered by 'the Commonwealth business culture'. The use of a unifying theme, 'Trade, Investment and Development - the Road to Commonwealth Prosperity', at the Edinburgh CHOGM appeared to be an attempt to rectify these inadequacies. In his opening statement, the Commonwealth SecretaryGeneral underlined the importance of this topic, stating that 20 per cent of global trade takes place within the Commonwealth. British Prime Minister Tony Blair supported the meeting's focus, emphasising at the Commonwealth Business Forum held in London in the week preceding CHOGM that the 'The Commonwealth should not be reluctant to take on an economic role and an economic profile'.

The trade, investment and development theme was reflected in a number of different facets of the Edinburgh CHOGM. First, at the Commonwealth Business Forum Britain's President of the Board of Trade, Margaret Beckett, outlined six key areas for improving Commonwealth cooperation including the creation of a Commonwealth Business Council to represent the views of the private sector, the provision of assistance for trade policy training to poorer Commonwealth countries, and the need to fight corruption. Second, during the course of the meeting a new investment fund for South Asia was launched, marking the third in a series of regional funds established under the Commonwealth Private Investment Initiative, a pan-Commonwealth initiative which has raised approximately US $\$ 200 \mathrm{~m}$ for investment in emerging Commonwealth economies.

In addition, a number of reports presented to the leaders dealt with matters relevant to the central focus. The Report of the Commonwealth Ministerial Group on Small States drew attention to the role of the Commonwealth in overcoming the vulnerability of small states, in particular their economic vulnerability. It emphasised the need to assist small states in coping with the costs of adjusting to the new international trade regime, and pointed to the consequences for small states of declining levels of official development assistance. The Report of the Committee of the Whole, which considered Commonwealth functional cooperation, included paragraphs on sustainable growth and development, and gender and development, and called for the Commonwealth Partnership for Technology Management to support CHOGM's work on trade, investment and development. Outside the 'official' Commonwealth, the Commonwealth Human Rights Initiative (CHRI), a nongovernmental organisation supported by six Commonwealth associations, urged the Heads of Government to adopt policies which further the realisation of economic and social rights and to promote the accountability and social responsibility of national and multinational businesses (CHRI, 1997:79-80). A feature of all these reports is the recognition that the Commonwealth must support policies and programs in trade and investment which account for the needs of its members in both the developed and the developing worlds.

Most significantly, the leaders adopted the Edinburgh Commonwealth Economic Declaration as a complement to the Harare Declaration. Not surprisingly 
for a document adopted by an organisation comprising many of the world's poorest countries, the Declaration's introduction proclaims that 'world peace, security and social stability cannot be achieved in conditions of deep poverty and growing inequality' (para. 2). The first section emphasises the organisation's support for the dismantling of trade barriers, the need to strengthen the World Trade Organisation and to maintain progress on agriculture, financial and other services 'taking into account the interests of all countries at different stages of development' (para. 4). The emphasis on developing countries is continued in the section devoted to investment, in which the leaders agree to support the development of regional and multilateral arrangements and infrastructure that take into account the realities of developing countries (para. 6).

The final paragraphs on development and the environment refer to the need to increase openness in economic decision-making and promote notions of sustainable development, with specific reference to the Kyoto summit. It has yet to be seen whether the Edinburgh Economic Declaration will achieve the same standing in the organisation's constitutional structure as the Harare Declaration. It may be that the Commonwealth's statements of 'support' for existing arrangements indicate that it will endorse rather than duplicate the efforts of other regional and international organisations in this field. On the whole, the documents emanating from the Edinburgh CHOGM demonstrate that the Commonwealth has recognised that opportunities exist to increase its influence, through either improving Commonwealth cooperation or assisting the trade and investment programs of other associations.

\section{Human Rights}

The Harare and Auckland CHOGMs made notable progress in both setting the human rights standards by which members are expected to abide and introducing procedures for supervising those standards through the Millbrook Action Programme and the establishment of CMAG. Prior to Edinburgh, the question was whether the leaders would live up to the promise of the 1991 and 1995 meetings by providing further guidance on the enforcement of the proclaimed standards, particularly in relation to their attitude towards Nigeria.

The suspension of Nigeria in 1995 demonstrated that current members may be required to abide by the Harare Declaration, despite the fact that the Intergovernmental Group on Criteria for Commonwealth Membership considered principles applicable only to future applicants. This view was reinforced at the Edinburgh CHOGM where Nigeria's record again came under discussion. The reports of CMAG's eight meetings demonstrated that it was in a dialogue with the Nigerian government and had obtained information about the situation of human rights and the rule of law in the country. The Group recommended the implementation of sanctions, including visa restrictions on members of the Nigerian regime and their families, an embargo on the export of arms and a downgrading of diplomatic missions. Despite these recommendations, the perceived lack of Commonwealth action on Nigeria has been condemned by human rights groups. CHRI deplored the failure of CMAG to make any impact on the Nigerian government, stating that the 
'Nigerian government has successfully exploited a weakness of resolve within the Commonwealth and threatens to undermine the credibility of the Harare Declaration and the Millbrook Plan of Action' (CHRI, 1997:112). Thus it was not until CMAG's report to the Edinburgh CHOGM that the Group, as the representative of the official Commonwealth, openly condemned the lack of progress, asserting that 'the continued existence of a military government in Nigeria constitutes the most blatant violation of the Harare principles' (para. 8).

CHOGM's decision to endorse CMAG's recommendations and continue $\mathrm{Ni}$ geria's suspension until 1 October 1998 , when consideration would be given to either lifting the suspension or expulsion, was denounced by those who believed that Nigeria should have been expelled on the basis of its record to date. The difference of opinion on the appropriate action to be taken on Nigeria reveals the difficulties faced by the Commonwealth in undertaking any enforcement measures against current members. The Commonwealth continues to assert its dependence on a 'family' atmosphere and the ability to use consensus decision-making as an appropriate method of accomplishing its goals. But these procedures sit uneasily in an organisation which may authorise the expulsion of one of its members in the near future. Expulsion is considered to be one of the harshest sanctions available to an international organisation. However, its effectiveness remains doubtful, given that once the organisation loses contact, it can no longer exert the same pressure on the exmember (Schermers \& Blokker, 1995:921). In the case of South Africa, after it had withdrawn from the organisation the Commonwealth was able to mobilisc international opinion on the apartheid policy. It remains to be seen whether the same approach would be effective in relation to Nigeria, if indeed it is expelled from the organisation. Such actions could fracture the Commonwealth's ability to build a consensus which gives the organisation its significant advantage when dealing with human rights concerns.

Despite the media attention generated by the situation in Nigeria, it is not the only country which has been subjected to CMAG's attention since its establishment in 1995, nor is it the only member with a doubtful human rights record. Both The Gambia and Sierra Leone have featured in CMAG's reports over the last two years and were subsequently cited in the 1997 Communiqué. The inclusion of these two countries in the communiqué indicated that by 1997 the practice of highlighting individual members' violations in official CHOGM documentation is no longer controversial. While the leaders limited their discussions to three countries, CHRI in its report The Right to a Culture of Tolerance casts a wider net, pointing to situations of religious and ethnic intolerance in Commonwealth countries and compiling a list of general recommendations for action. The report suggested that six years after the 1991 meeting some progress had been made in human rights, although the Harare principles were still being 'blatantly disregarded' in too many instances

In relation to Sierra Lcone the leaders endorsed CMAG's recommendation to invoke the exclusion clause of the Millbrook Action Programme, barring representatives of the Sierra Leone regime from participating in Commonwealth councils (Communiqué, para. 17). 
(CHRI, 1997:79). The approach of CHRI differs fundamentally from that of CMAG in that it is willing to consider a range of problems and enumerate abuses in a number of countries. This dichotomy between the reports of the two bodics demonstrates that CMAG as the representative of the official Commonwealth is still (at least partially) constrained by the traditional limitations imposed by the organisation's policy of non-interference in the domestic affairs of member states. It has yet to be determined whether the additional power given to the Secretary-General at the Edinburgh CHOGM, enabling serious violations of the Harare Declaration to be brought to CMAG's attention, will result in an extension of the Commonwealth's ability to inquire into its members' human rights records, and whether such an extension is desirable.

\section{Australia and the Commonwealth After the Edinburgh CHOGM}

The Australian media coverage of CHOGM was dominated by the Prime Minister John Howard's 'victory' in achieving recognition for differentiation in greenhouse gas emission targets prior to the Kyoto conference. Among other issues discussed at Howard's press conferences were the continued suspension of Nigeria, Australia's proposal to host the $2001 \mathrm{CHOGM}$, and South African President Nelson Mandela's offer to assist in reconciling Aboriginal communities and the government over the Wik legislation. ${ }^{7}$ The Foreign Minister, Alexander Downer, viewed the meeting as a success, stating that it 'helped advance our regional and global interests in practical ways'. However, at the same time he recognised that it is true that the Commonwealth is not at the centre of Australia's foreign and trade policy priorities in the way that the Asia Pacific is' (Downer, 1997). This view is certainly reinforced by the fact that the Commonwealth rates only one mention in Australia's Foreign and Trade Policy White Paper, In the National Interest (DFAT, 1997), which is clearly focused on opportunities available to Australia through its membership of other organisations.

Downer's positive assessment of the specific benefits for Australia in attending CHOGM appears to be based on Australia's ability to use the meeting as a forum to strengthen relations with both developed and developing nations and form personal contacts on a more informal basis. Going beyond CHOGM, a Department of Foreign Affairs and Trade paper, The Commonwealth and Australia, elaborates on the advantages of Commonwealth membership stating that 'Australia has emphasised the role of the Commonwealth as a useful multilateral vehicle, as long as it focuses its activities on areas in which it has genuine comparative advantage' (DFAT, n.d.). According to this paper, these activities include the promotion of fundamental political values, the provision of electoral assistance and technical assistance, the exchange of legal information, and cooperation in health and education. However, Prime Minister Howard went beyond this list of topics at Edinburgh in

\footnotetext{
${ }^{7}$ CHRI's report includes a section titled 'Australia lags behind on land rights' stating that in proposing the Wik legislation 'Australia risks its reputation in the intenational community where memories of the White Australian policy and historic persecution of Aborigines linger' (CHRI, 1997:39).
} 
pursuing issues such as the environment, raising the question of whether the Commonwealth is the most appropriate forum for voicing such concerns in Australia's foreign policy.

In order to discuss the place of the organisation in Australia's foreign policy and highlight its activities, in 1997 the Joint Standing Committee on Foreign Affairs, Defence and Trade held a seminar on the Commonwealth. The report emanating from this seminar made a number of suggestions for improving the Commonwealth's profile (Joint Standing Committee on Foreign Affairs, Defence and Trade, 1997:ix-xi). The first recommendations focused on the need to increase public knowledge about the Commonwealth in Australia through the establishment of a Commonwealth resources centre and an association for Commonwealth studies. A second group of suggestions dealt with the possibility of establishing regional meetings of both Commonwealth Heads of Government and Trade Ministers. Additionally, the Committee submitted that the Australian government should promote the strengthening of the Human Rights Unit in the Commonwealth Secretariat. These recommendations match the conclusions of the Foreign Affairs Committee of the British House of Commons when it stated 'that the Commonwealth is acquiring a new significance in a rapidly transforming world and ... United Kingdom policy-makers should bring this major change to the forefront of their thinking' (Saunders, 1996:288). It has yet to be seen whether Australia will adopt the proposals of the Joint Standing Committee and promote a more substantial role for the Commonwealth in its foreign policy. If Australia chooses to follow these recommendations, it will need to determine the extent to which its foreign policy objectives can be pursued through the organisation in areas where it believes that it offers a 'genuine comparative advantage'.

\section{Conclusion}

Saunders (1996:287) has commented that the Commonwealth's capacity to survive into the 21 st century will depend on its ability to meet the challenges and opportunities that confront it over the next few years. The use of a central theme at the Edinburgh CHOGM indicated that the Commonwealth has perceived a new opportunity to promote the organisation's advantages in the area of trade, investment and development. The challenge in adopting the Edinburgh Economic Declaration was to reconcile and accommodate the needs of both the developed and the developing members and to recognise the special position of small states. In relation to the human rights program, the leaders in Edinburgh needed to demonstrate that the Harare Declaration and Millbrook Action Plan were not empty rhetoric, but were successfully designed to deal with aberrant behaviour among the membership. The continued suspension of Nigeria as opposed to expulsion, despite its lack of progress towards democracy, suggests that the organisation is still ambivalent about its role in investigating and condemning matters traditionally believed to be within a member's internal affairs. Both issues demonstrate that the Commonwealth must define its position as an international organisation to ensure that its contribution complements the work of other organisations without exceeding its capabilities. 
The ability of the Heads of Government to reduce any gap between rhetoric and reality in the Commonwealth's economic and human rights programs will determine its capacity to maintain public confidence and thus meet the challenges of the 21 st century.

\section{References}

Alley, R. (1997), 'Fiji at the Crossroads? After the Constitutional Review Commission' The Round Table: 245-56.

Anyaoku, E. (1996), 'Human Rights and the Commonwealth', address at the launch of the Graduate School of Intemational Relations at the University of Kent, London School of Economics and Political Science, 9 May.

Chan, S. (1992), 'The Commonwealth as an International Organization', pp. 3-25 in J. Alner (ed.), Twelve Years of Commonwealth Diplomatic History, Commonwealth Summit Meetings 1979. 199I, Edwin Mellen Press Ltd, Lewiston.

Collinge, J. (1996), 'Criteria for Commonwealth Membership', The Round Table: 279-86.

Commonwealth Human Rights Initiative (CHRI) (1997), The Right to a Culture of Tolerance, New Delhi.

Dale, W. (1982), 'Is the Commonwealth an International Organization?', International and Comparative Law Quarterly 31: 451-73.

Department of Foreign Affairs and Trade (DFAT) (1997), In the National Interest: Australia's Foreign and Trade Policy White Paper, Commonwealth of Australia, Canberra.

- (n.d.), The Commonwealth and Australia

http://orpheus.dfatgov.au/policy/intorg/aus_comm.html

Downer, A. (1997), 'The Edinburgh CHOGM: Outcomes and Implications for Australia', Speech to the ACT Branch of the Commonwealth Society, 27 November.

Duxbury, A. (1997), 'Rejuvenating the Commonwealth - The Human Rights Remedy', International and Comparative Law Quarterly 46: 344-77.

Ingram, D. (1994), 'Limassol Notebook', The Round Table: $13-16$.

Joint Standing Committee on Foreign Affairs, Defence and Trade (1997), From Empire to Partnership, Parliament of the Commonwealth of Australia, Canberra.

McIntyre, W. (1991), The Significance of the Commonwealth 1965-90, Canterbury University Press, Christchurch.

Saunders, R. (1996), 'The Commonwealth Must Not Wake Up Feeling Terrible', The Round Table: 287-94.

Schermers, H. \& N. Blokker (1995), International Institutional Law (3rd ed.), Nijhoff, The Hague.

West, K. (1995), Economic Opportunities for Britain and the Commonwealth, The Royal Institute of International Affairs, London. 